\title{
Granular Cell Odontogenic Tumour - A Histopathological Rarity
}

\author{
Nagahimabindu Vennamaneni*, K Padma Priyanka, Sumit Majumdar and Divya Uppala \\ Department of Oral Pathology and Microbiology, Gitam Dental College \& Hospital, India
}

Submission: June 06, 2016; Published: June 28, 2016

"Corresponding author: Nagahimabindu Vennamaneni, Department of Oral Pathology and Microbiology, Post Graduate Student, Gitam Dental College \& Hospital, Rushikonda, Visakhapatnam-530045, Andhra Pradesh, India, Tel: 9492343142; Email: himabindumds@gmail.com

\begin{abstract}
Central Granular Cell Odontogenic Tumour (CGCOT) is an uncommon benign odontogenic neoplasm. It predominantly occurs in middle aged women. We report a case of CGCOT that occurred in the mandible of a 38 year old male patient. Clinical, radio graphical, histopathological features and immunohistochemical investigations like Calretinin, AE1/AE3, S100 and Neuron Specific Enolase (NSE) were described.

Keywords: GCOT; Granular cells; Odontogenic tumor; Intra osseous

Abbreviations: GCOT: Central Granular Cell Odontogenic Tumour; NSE: Neuron Specific Enolase; OPG: Orthopantomograph; irt: in relation to
\end{abstract}

\section{Introduction}

Central Granular Cell Odontogenic Tumour (CGCOT) is a rare, benign, slowly growing, noninvasive but unencapsulated odontogenic neoplasm [1]. So far 39 cases were reported in the literature $[2,3]$. It represents $0.3 \%$ of odontogenic tumors. Most commonly seen in the posterior region of the mandible with a predilection between premolar-molar region. It shows a predilection for middle-aged women [2]. In this article, we described CGCOT that occurred in a 38 year old male patient.

\section{Materials and Methods}

0.3 microns thick sections were obtained from paraffin embedded tissues that had been processed, stained with protein Hematoxylin and eosin stains. These stained sections were then reviewed.

\section{Case Report}

A 38-year old male patient came with a chief complaint of pain in lower right back tooth region since 4 months. There was no obvious extra oral and intra oral swelling. Orthopantomograph (OPG) revealed a well defined unilocular radiolucency in relation to (irt) the apical region of 44 to 46 . Root resorption was evident irt 45 and mesial root of 46 (Figure 1). Aspiration was negative. Excision biopsy was done for histopathological examination which showed a grayish white surface (Figure 2). Microscopic examination of Haematoxylin \& Eosin stained soft tissue sections revealed islands of odontogenic epithelium surrounded by thin fibrocellular connective tissue (Figure 3). Epithelial islands showed large central cells, with granular eosinophillic cell cytoplasm and eccentrically placed nucleus (Figure $4 \& 5$ ). Peripheral cells of the island are cuboidal to low columnar in shape without any nuclear palisading and reverse polarization (Figure 6). The connective tissue is interspersed with odontogenic epithelial rests. In the differential diagnosis we included granular cell ameloblastoma.

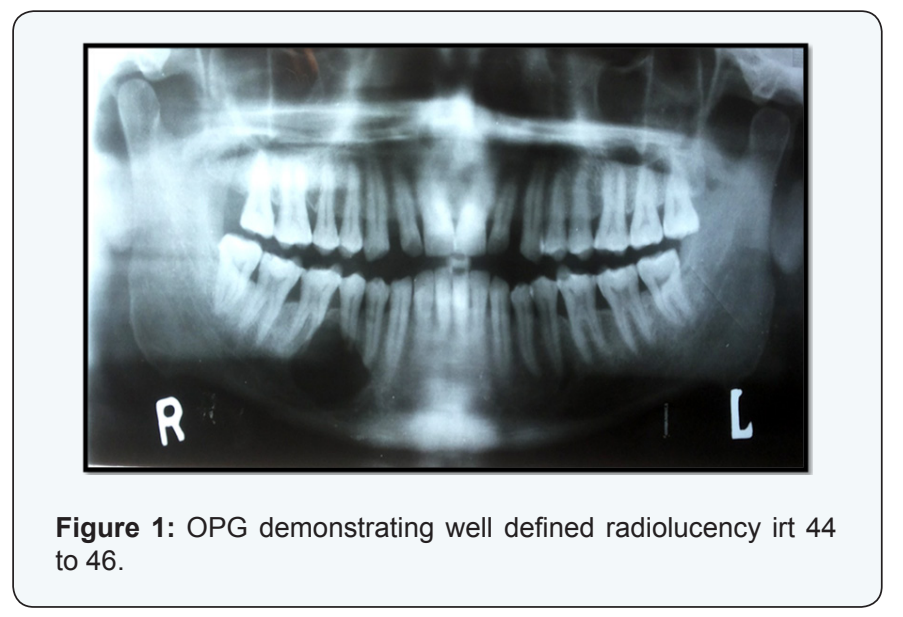




\section{Organic and Medicinal Chemistry International Journal}

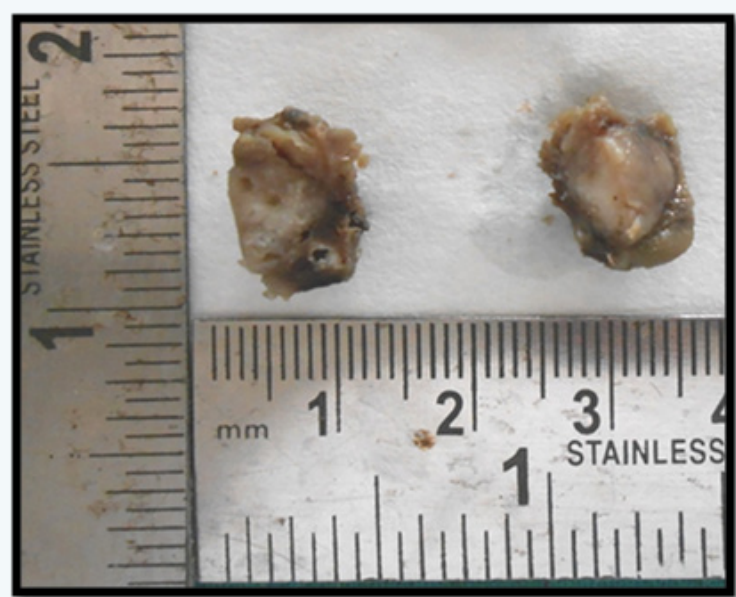

Figure 2: Grayish white cut surface.

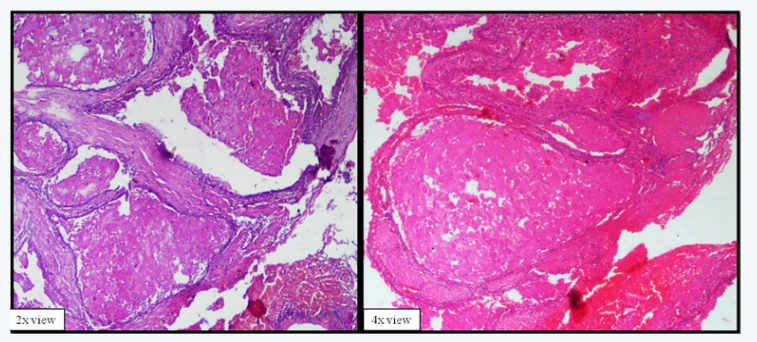

Figure 3: Epithelial islands surrounded by connective tissue. H\& E stain.

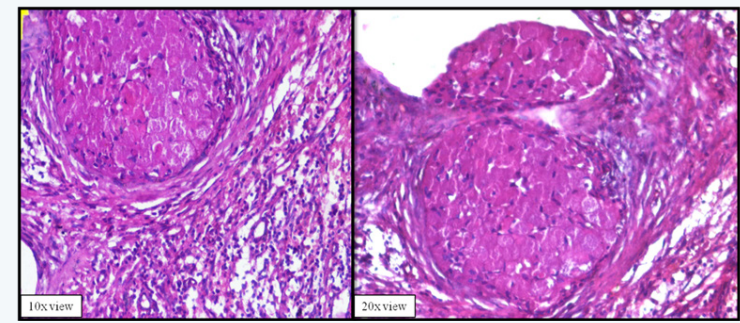

Figure 4: Central cells- with granular cytoplasm and eccentrically placed nucleus.

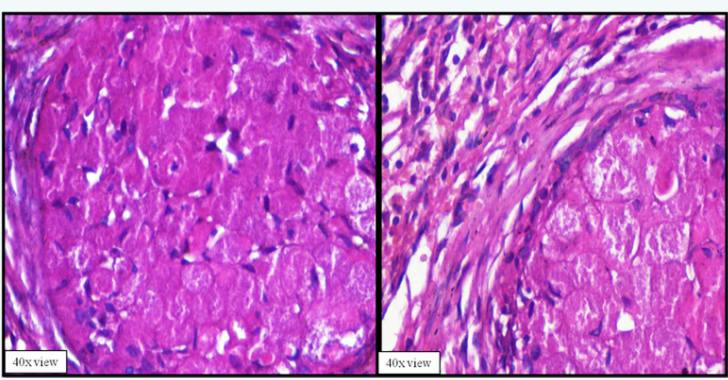

Figure 5: central cells- with granular cytoplasm and eccentrically placed nucleus.

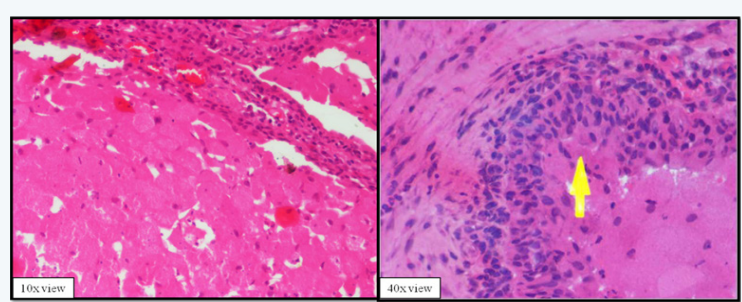

Figure 6: Cuboidal to low columnar peripheral cells without reverse polarization. (40x view: $\mathrm{H}$ \& $\mathrm{E}$ stain).

Immunohistochemical investigations were performed (Figure7). Calretinin was negative, Pan CK (AE1/AE3) was positive in peripheral cells and negative in central granular cells, which are in distinction with the granular cell ameloblastoma. As granular cell ameloblastoma shows positive calretinin staining and CK staining in both peripheral and central cells. Hence we ruled out granular cell ameloblastoma. S-100, NSE were negative, suggesting that GCOT is a distinct entity compared with granular cell tumour of the soft tissues. Overall radiographical, histopathological and immunohistochemical findings were confirmative of diagnosis of CGCOT. Enucleation of the lesion was done. Healing was uneventful and no recurrence was seen.

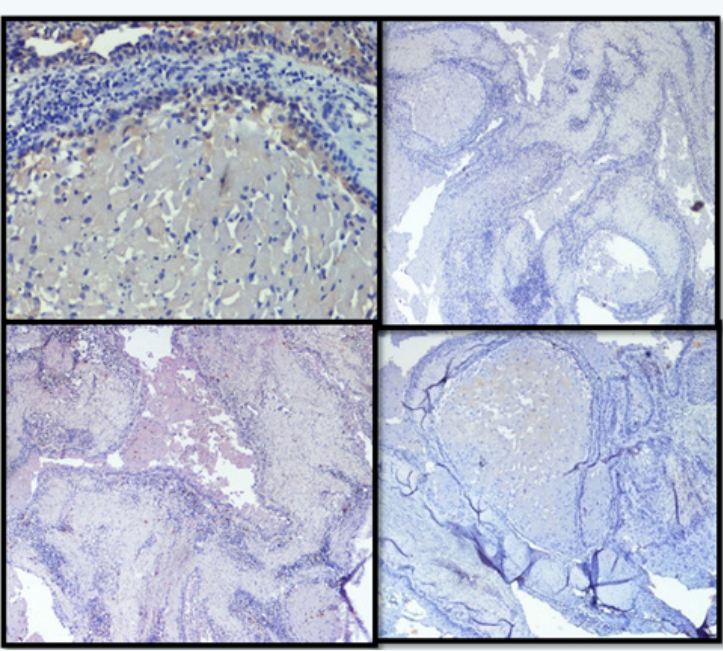

Figure 7: A Pan CK- positive, B Calretinin, C S-100, D NSE negative.

\section{Discussion}

It was first described by Werthemann in 1950, who used the term 'spongiocytic adamantinoma',Couch et al. in 1962 described it as 'Granular cell ameloblastic fibroma', Dalforno and Donna in 1970 referred it as 'Ameloblastic fibroma with stroma of granular cells', White et al. in 1978 termed it as 'Central granular cell tumor of the jaws', Vincent et al. in 1987 termed it as 'Central granular cell odontogenic fibroma', 


\section{Organic and Medicinal Chemistry International Journal}

Shiro et al. in 1989 and WHO 2005 considered the term 'Central granular cell odontogenic tumor [2]. Tumours that predominantly composed of granular cells with ameloblastic and/or odontogenic features have been considered a distinct entity and named it as GCOT [4]. But it was not included in the WHO 2005 classification of odontogenic tumors [1].

It occurs over a wide age range of 16- 77 years with a mean age of 45.21 years. Most of the cases were seen in the 5th to 7 th decades. Female: Male distribution is 3.1:1. 72.02\% of cases were reported in mandible and $27.7 \%$ in maxilla. Size of the tumor ranges from 0.5 to $8.0 \mathrm{~cm}$. Duration ranges from 5 months to 19 years [2].

Some lesions are completely asymptomatic and others appear as a painless mass with localized expansion. Very few number of GCOTs that occurred in gingiva were also reported [5]. It was mainly reported in blacks and whites, Chiang et al reported a first case of GCOT in oriental people [6]. GCOT presents usually as well defined unilocular or multilocular radiolucency, with or without focal areas of opacity [5].

Histopathologically, it is characterized by sheets and clusters of round to polygonal cells with abundant, finely granular, eosinophillic cell cytoplasm and eccentrically placed nucleus without any mitoses. Peripheral cells are low columnar or cuboidal cells. Stellate reticulum like cells are absent. These features are correlating with our case. Occasionally dystrophic calcifications may be seen [1].

Meer et al suggested that the granular cells are Mesenchymal in origin (vimentin positive) and derived from a histiocytic cell line [7]. Gomes et al supported histiocytic differentiation of the granular cells, as they showed the strong expression of the CD68 [8]. Granular cells ultra structurally showed few cytoplasmic organelles and abundant electron dense intracytoplasmic lysosome-like particles [9]. Takeda et al suggested that granular changes represent degenerative or aging rather than neoplastic nature of Granular Cells [10].
Most of these cases were treated by Enucleation and curettage. These lesions were easily enucleated and recurrence rate is very less. Prognosis is good [11].

\section{Conclusion}

As intraosseous granular cell neoplasms are rare, diagnosis should be made cautiously. As the treatment plan and prognosis varied widely, when compared with that of granular cell ameloblastoma.

\section{References}

1. Barnes L, Eveson JW, Reichart P, Sidransky D, (Eds.) (2005) Histological typing of odontogenic tumours. Lyon: IARC Press p. 308.

2. Sarode SC, Sarode GS, Vaidya K (2014) Central granular cell odontogenic tumor: a systematic review. J Oral Pathol Med 43(3):167-176.

3. Anbiaee N, Saghafi S, Rezaei MM (2014) Central Granular Cell odontogenic Tumor: Report of a Case

4. with CBCT Features. Journal of Dentistry 11(3): 365-370.

5. Reichart PA, Philipsen HP (2004) Odontogenic tumours and allied lesions. Berlin: Quintessence 36(7): 383-446.

6. Neville B, Damm D, Allen C, Bouquot J (2009) Granular cell odontogenic tumor. In: Textbook of Oral and Maxillofacial Pathology ( $3^{\text {rd }}$ edn), Philadelphia Saunders p. 729.

7. Chiang CT, Hu KY, Tsai CC (2014) Central granular cell odontogenic tumor: The first reported case in Oriental people and literature review. J Formos Med Assoc 113(5): 321-325.

8. Meer S, Altini M, Coleman H, Daya N (2004) Central granular cell odontogenic tumor: immunohistochemistry and ultrastructure. Am J Otolaryngol 25(1): 73-78.

9. Gomes CC, Naves MD, Pereira MV, Silva LM, Mesquita RA, et al. 2006 Granular cell odontogenictumour: Case report and review of literature. Oral Oncology Extra 42(8): 277-280.

10. Brannon RB, Goode RK, Eversole LR, Carr RF (2002) The central granular cell odontogenic tumor: report of 5 new cases. Oral Surg Oral Med Oral Pathol Oral Radiol Endod 94(5): 614-621.

11. Takeda Y (1999) Ameloblastic fibroma and related lesions: current pathologic concept. Oral Oncol 35(6): 535-540. 